
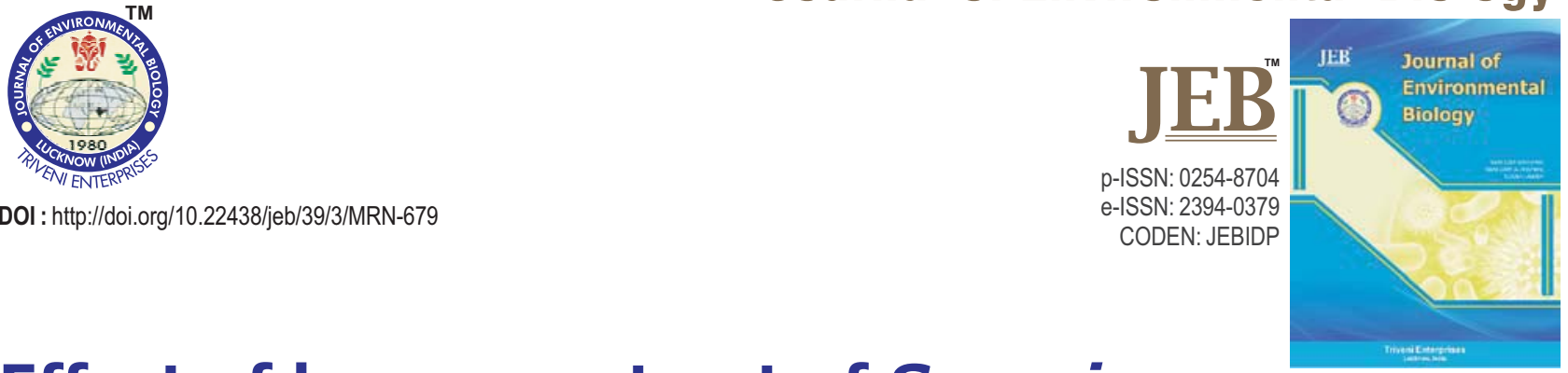

\title{
Effect of hexane extract of Syzygium aromaticum on haematological profile of rats
}

\section{Authors Info}

\section{S. Arora ${ }^{1}$, M. Pal ${ }^{2}$, M. Bordoloi ${ }^{3}$ and S. P. Nandi ${ }^{1 *}$}

${ }^{1}$ Amity Institute of Biotechnology, Amity University, Noida-201 313, India

${ }^{2}$ Division of Forensic Science, School of Basic \& Applied Sciences, Galgotias University, Greater Noida-201 306, India

${ }^{3}$ Natural Product Chemistry Division, CSIR-North East Institute of Science \& Technology, Jorhat-785 006, India

*Corresponding Author Email : spaul@amity.edu

Key words

Haematology

Platelet indices

Rat

$\mathrm{RBC}$ indices

Syzygium aromaticum

Publication Info

Paper received : 17.06.2017

Revised received : 23.08 .2017

Re-revised received: 08.09.2017

Accepted : 25.09.2017

\section{Abstract}

Aim : To analyse the effect of hexane extract of Syzygium aromaticum on haematological profile of rats.

Methodology : Previously, hexane extract of $S$. aromaticum buds at a high dose of $5000 \mathrm{mg} \mathrm{kg}^{-1}$ was given to one rat and the corresponding control received saline water as vehicle. It was repeated and no mortality was observed. Based on the result, $2000 \mathrm{mg} \mathrm{kg}^{-1}$ was selected for the main study. The rats were prorated into two groups (control and treated). Each group consisted of six rats. After administration of hexane extract, blood was collected from three rats per group at an interval of $1 \mathrm{hr}$ (retero-orbital plexus); $24 \mathrm{hrs}$ and 14 day (cardiac puncture) in ethylenediaminetetraacetic acid coated vials and signs of toxicity and mortality were observed in animals. Haematological parameters were estimated from collected blood samples using automatic haematological analyser (Model Melet Schloesing MS4).

Results : The hexane extract of $S$. aromaticum at a dose of $2000 \mathrm{mg} \mathrm{kg}^{-1} \mathrm{~b}$. wt. to male rats did not produce any change in haematological profile for $1 \mathrm{hr}$ exposure. The changes were observed in monocytes and white blood cells after $24 \mathrm{hrs}$. Significant $(P<0.05)$ changes were observed in red blood cells, haemoglobin, hematocrit, platelets, plateletcrit and platelet distribution widths after 14 days of treatment. The treated rats neither exhibited any signs of toxicity nor death during 14 days of study.

Interpretation : The results revealed that a single dose of $2000 \mathrm{mg} \mathrm{kg}^{-1}$ of Syzygium aromaticum did not induce any impact on haematological profile of rats till 14 day after administration of hexane extract.

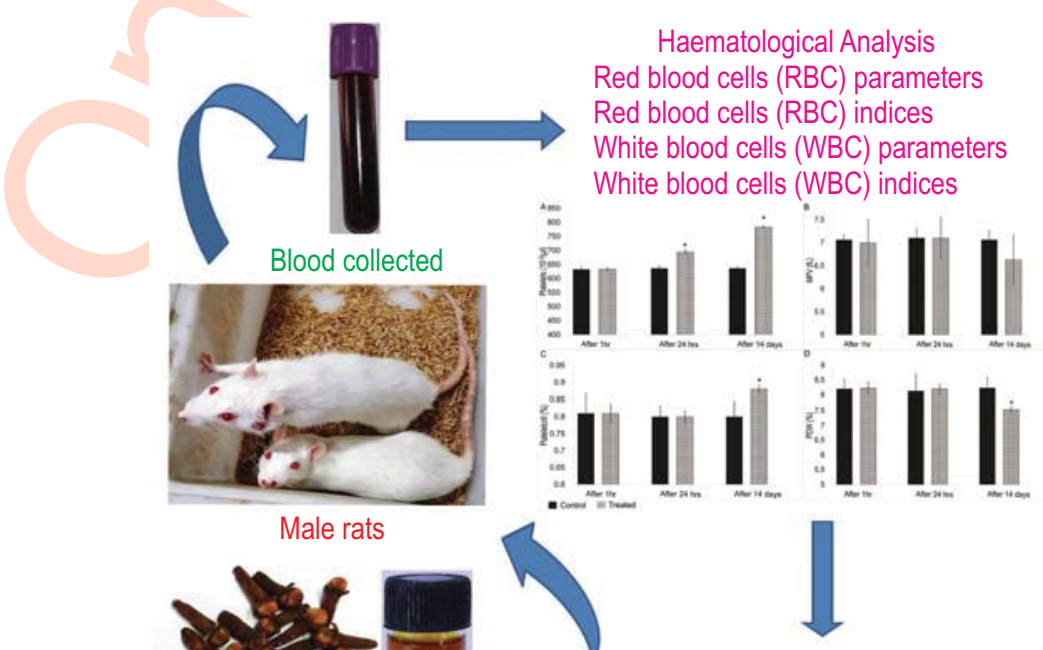

Hexane extract of clove did not possess any potential of inducing changes on the blood profile of rats during short term exposure 


\section{Introduction}

Natural products play an important role in traditional healing from centuries till date (Petrovska, 2012). The majority of population depends on herbal medicines rather than opting for other treatments due to high cost and side-effects associated with it. Eighty percent of the world population prefers to use medicinal plants to treat their ailments (Ekor, 2014). Herbal products are being consumed for centuries without knowing the risk of its usage and also documentation is still scanty on the toxicity and dosage of these products.

Syzygium aromaticum (clove) is an evergreen tree (8-12 m tall) belonging to family Myrtaceae native to Maluku Islands in Indonesia and harvested in different Asian Countries like India, Sri Lanka, Bangladesh, Pakistan and Tanzania (Kamatou et al., 2012). S. aromaticum buds have antibacterial (Sofia et al., 2007; Dorman et al., 2000) antioxidant (Shan et al., 2005; Gulcin et al., 2012; Dudonne et al., 2009; Gulcin et al., 2004), antifungal (Rana et al., 2011) and anticarinogenic properties (Aggarwal et al., 2006; Ghosh et al., 2005). It is commonly used for toothache and throat inflammation (Cai and Wu, 1996; Jadhav etal., 2004). Other uses of clove oil include treatment of intestinal diseases, cure against impotency, infertility (Nadkarni, 2000) and relaxant property of smooth muscles (Damiani et al., 2003). Clove oil consist of gallic acid and acetyleugenol, methyl-n-amyl ketone, sesquiterpenes, vanillin, furfural and oleanolic acid, flavonoids, lipids, resin rhamnetin, carbohydrates, vitamins, tannins and gums (Chaieb et al., 2007). Bioactive constituents present in S. aromaticum are essential oil 12-16\% (v/w) and phenolic compounds. Halder et al. (2011) reported that clove oil is capable of reverting back memory and learning deficits by reducing oxidative stress. Presence of large number of phytochemicals and secondary metabolites have encouraged the researchers to explore many new applications of clove oil (Vijayasteltar etal., 2016).

Oral administration of water extract of $S$. aromaticum buds at different doses has been reported to be toxic but not fatal, emphasising its effect on growth, serological, pathological and haematological features in Wistar rats (Adam et al., 2013). Determination of effect of foreign component (plant extract) in blood can be estimated using haematological parameters (Olson et al., 2000). Investigation on blood parameters provides immediate information on the health impact of a product. Studies on haematological parameters are therefore important to establish a relationship between test products with physiology of body (Parma et al., 2007). The objective of the present research was to estimate various haematological parameters in male rats after oral administration of hexane extract of $S$. aromaticum.

\section{Materials and Methods}

Plant extract preparation : Dry flower buds of $S$. aromaticum were washed thoroughly with water and air dried at room temperature. The extraction procedure as described by Handa et al. (2008) was followed. Ten gram of clove was powdered using mortar and pestle and immersed in $40 \mathrm{ml}$ hexane at room temperature for $16 \mathrm{hrs}$. The extract was then filtered. The procedure was repeated three times. The combined filtrate was evaporated with the help of vacuum at $50^{\circ} \mathrm{C}$ using rotary evaporator to achieve a concentrate that could be stored at $4^{\circ} \mathrm{C}$ for future use.

Test animals : Healthy Sprague-Dawley rats $(n=12)$ weighing 140-160 $\mathrm{g}$ were selected for the study. The rats were housed in cages at controlled room temperature of $22-24^{\circ} \mathrm{C}$, relative humidity between $40-60 \%$ and a constant schedule of light: dark: $12 \mathrm{hr}: 12 \mathrm{hr}$ cycles. The animals were fed with pelleted food supplied by Golden Feeds Delhi, India and water ad libitum. The experimental protocol was approved through Institutional Animal Ethics Committee (IAEC) of Institute of Nuclear Medicine and Allied Sciences (INMAS), Defence Research and Development Organization (DRDO), Delhi.

Experimental procedure : Experimental animals were divided into two groups (control and treated) containing six rats in each group. Before the actual experiment, two rats were taken, one of them was treated with $5000 \mathrm{mg} \mathrm{kg}^{-1}$ of hexane extract of clove and the other one received saline water as vehicle and both were checked for mortality. The experiment was repeated twice. In both sets of experiment the animals survived. Based on the observation, $2000 \mathrm{mg} \mathrm{kg}^{-1}$ of dose was selected for the main study. Hexane extract was orally administered to the experimental groups, whereas control group was treated with saline. Blood was withdrawn into EDTA coated vials after $1 \mathrm{hr}$ of treatment from retero-orbital plexus of three rats, one each from experimental and control group. After $24 \mathrm{hrs}$, blood was redrawn from the same rats by cardiac puncture and the rats were sacrificed. Similar steps were repeated after 14 day. Rats were observed daily for signs of toxicity, if any, during 14 days of experiment.

Haematological investigations : The collected blood was used for analysis of Red Blood Cell (RBC) counts, Haemoglobin (HGB) concentration, White Blood Cell (WBC) counts, Lymphocytes (LYM), Monocytes (MCT), Granulocytes (GRA), Platelets Count (PTL), Haematocrit (HCT) level, Red Cell Distribution Width (RDW), Mean Platelet Volume (MPV), Mean Corpuscular Volume (MCV), Mean Corpuscular Haemoglobin ( $\mathrm{MCH})$, Mean Corpuscular Haemoglobin Concentration (MCHC), Plateletcrit (PCT) and Platelet Distribution Widths (PDWs) using automatic haematolyzer (Model Melet Schloesing MS4 in Department of Biochemical Sciences, Defence Institute of Physiology and Allied Sciences, Delhi, India).

Statistical analysis : The values obtained for different haematological parameters were expressed as mean \pm SD. Student's t-test was used to determine statistical significance between the difference of mean of treated and control groups.

\section{Results and Discussion}

Analysis of haematological parameters is used to determine the physiological response in blood. It also provides 
immediate information of undesirable effect of chemical compounds or herbal products and these systematic researches have been reported to be extremely accurate, sensitive and reliable (Olson et al., 2000). In view of this, the present study was conducted to assess the effect of hexane extract of $S$. aromaticum on haematological profiles.

The dose (2000 mg of hexane extract of $S$. aromaticum $\mathrm{kg}^{-1}$ body wt.) was selected based on previous study where no mortality was observed when treated with $5000 \mathrm{mg} \mathrm{kg}^{-1}$ in two sets of experiment. Moreover, Agbaje et al. (2009) also reported 2500 $\mathrm{mg} \mathrm{kg}^{-1}$ b. w.t. as oral LD 50 value in rats for $S$. aromaticum.

Administration of $S$. aromaticum hexane extract did not produce any significant $(P>0.05)$ change in lymphocytes or granulocytes whereas significant increase of $15 \%$ in monocytes was observed after $24 \mathrm{hrs}$ in treated group and $1 \%$ decrease in white blood cells was observed in treated group after 14 day of treatment when compared with control $(P<0.05)$ (Table 1). The response could be due to the demand for tissue macrophages which helps in regulating hameostatic condition created due to chemical compounds present in the extract (Gordon et al., 2017). The presence of certain phytocompounds with the ability to stimulate the production of white blood cells could be another reason for improved level of monocytes (Oyedemi et al., 2011). Short term exposure and low dose of hexane extract of $S$. aromaticum in our study showed no significant changes in white blood cells, lymphocytes or granulocytes thereby indicating no immune boosting effect. Earlier reports indicated that some commonly chosen medicinal plants like mistletoe, round-leaved vine contain factors that trigger the production of white blood cells (Imoru et al., 2005; Al-Mamary, 2002; Ladokun et al., 2015).

RBC and HGB play a key role in transferring respiratory gases (De Gruchy, 1976). The hexaneextract of S. aromaticum has significant $(P<0.05)$ increase of $37 \%$ in RBC, $21 \%$ in HGB and $25 \%$ in HCT after 14 days of treatment when compared with the control, whereas no significant $(P>0.05)$ change in RDW was observed in treated group when compared with the control group (Table 2). Agbaje et al. (2009) has reported change in RBC, HCT and HGB by the $S$. aromaticum extract due to free radical scavenging effect of flavonoids. A possible condition in such case may be that there is competition between the active constituent flavonoids and haemoglobin in RBC for oxygen and hypoxial condition accelerated the production of RBC. Another important activity possessed by the product of $S$. aromaticum is the direct stimulation of kidney which causes formation and secretion of erythropoietin (Sanchez-Elsner et al., 2004). It is interesting to note that Adam et al. (2013) also reported increase in RBC and haemoglobin using aqueous extract of $S$. aromaticum.

No significant difference of the hexane extract of $S$. aromaticum was found there on red blood cell indices (RBC indices) - MCV, MCH and MCHC (Fig. 1) when compared with the control group ( $P>0.05)$. These RBC indices were not affected because may be no change on haemoglobin weight per red blood cell and also in average weight of red blood cell (Agbaje et al., 2009). In most of the animals MCV, MCH and MCHC - red blood cell indices have a particular role in diagnosis of anaemia (Coles,

Table 1 : Effect of $S$. aromaticum hexane extract on various parameters of white blood cells in rats

\begin{tabular}{|c|c|c|c|c|c|c|}
\hline \multirow[b]{2}{*}{ Parameters } & \multicolumn{2}{|l|}{ After $1 \mathrm{hr}$} & \multicolumn{2}{|l|}{ After $24 \mathrm{hrs}$} & \multicolumn{2}{|c|}{ After 14 days } \\
\hline & Control & Treated & Control & Treated & Control & Treated \\
\hline WBC $\left(10^{-3} / \mu \mathrm{l}\right)$ & $7.42 \pm 0.04$ & $7.46 \pm 0.12$ & $7.42 \pm 0.08$ & $7.67 \pm 0.09$ & $7.46 \pm 0.02$ & $7.39 \pm 0.01^{*}$ \\
\hline Lymphocytes (\%) & $82.96 \pm 1.17$ & $84.03 \pm 1.44$ & $82.36 \pm 2.44$ & $81.56 \pm 2.10$ & $81.7 \pm 1.63$ & $82.96 \pm 1.13$ \\
\hline Monocytes (\%) & $0.81 \pm 0.01$ & $0.86 \pm 0.02$ & $0.79 \pm 0.01$ & $0.91 \pm 0.03^{*}$ & $0.81 \pm 0.01$ & $0.87 \pm 0.02$ \\
\hline Granulocytes (\%) & $2.16 \pm 0.18$ & $1.96 \pm 0.11$ & $2.26 \pm 0.18$ & $2.20 \pm 0.28$ & $2.26 \pm 0.19$ & $2.20 \pm 0.24$ \\
\hline
\end{tabular}

Values are mean \pm SD of three animals. *indicates significant difference $(P<0.05)$ between control and treated as obtained by Student's t-test

Table 2 : Effect of $S$. aromaticum hexane extract on various parameters of red blood cells in rats

\begin{tabular}{|c|c|c|c|c|c|c|}
\hline \multirow[b]{2}{*}{ Parameters } & \multicolumn{2}{|l|}{ After $1 \mathrm{hr}$} & \multicolumn{2}{|l|}{ After $24 \mathrm{hrs}$} & \multicolumn{2}{|c|}{ After 14 days } \\
\hline & Control & Treated & Control & Treated & Control & Treated \\
\hline $\operatorname{RBC}\left(10^{-6} / \mu \mathrm{l}\right)$ & $5.47 \pm 0.05$ & $5.58 \pm 0.01$ & $5.38 \pm 0.06$ & $6.5 \pm 0.25$ & $5.58 \pm 0.05$ & $7.63 \pm 0.11^{*}$ \\
\hline HCT $(\%)$ & $35.9 \pm 1.4$ & $35.8 \pm 0.49$ & $36.16 \pm 2.1$ & $38.7 \pm 0.42$ & $36.86 \pm 2.05$ & $46.1 \pm 0.46^{*}$ \\
\hline RDW (\%) & $8.23 \pm 0.15$ & $8.33 \pm 0.01$ & $8.43 \pm 0.08$ & $8.56 \pm 0.18$ & $8.33 \pm 0.04$ & $8.3 \pm 0.14$ \\
\hline HGB (g/dl) & $12.43 \pm 0.27$ & $12.6 \pm 0.05$ & $12.46 \pm 0.23$ & $13.66 \pm 0.80$ & $12.56 \pm 0.18$ & $15.23 \pm 0.13^{*}$ \\
\hline
\end{tabular}

Values are mean \pm SD of three animals. *indicates significant difference $(P<0.05)$ between control and treated as obtained by Student's t-test 


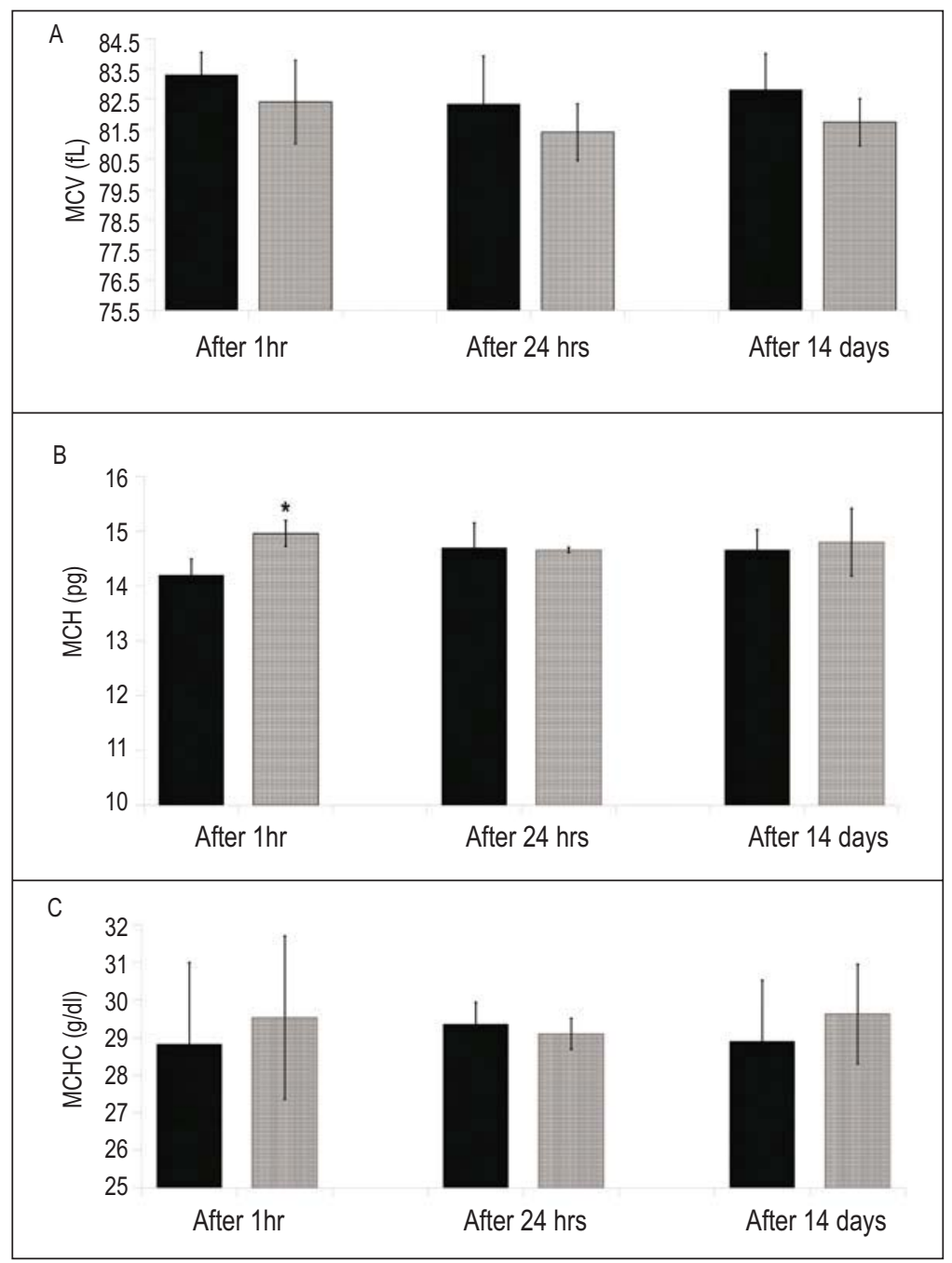

Control Treated

Fig. 1 : Effect of $S$. aromaticum hexane extract on red blood cell indices in rats. A: Mean Corpuscular Volume (MCV), B : Mean Corpuscular Haemoglobin $(\mathrm{MCH})$ and $\mathrm{C}$ : Mean Corpuscular Haemoglobin Concentration (MCHC). Values are mean \pm SD of three animals. *indicates significant difference $(P<0.05)$ between control and treated as obtained by Student's t-test

1986). The insignificant effect on these indices relating to red blood cell proposes that there was no change on haemoglobin weight per red blood cell and also in average weight of red blood cell. This suggests that the hexane extract did not induce anaemia throughout the period of treatment.

There was significant increase of $9 \%$ and $23 \%$ in platelets count after 24 hrs and 14 days of treatment respectively and $10 \%$ increase in plateletcrit after 14 days of treatment; whereas $8.5 \%$ decrease was seen in PDW percentage after 14 days of treatment with hexane extract of $S$. aromaticum when compared with control $(P<0.05)$. There is no significant difference in MPV $(P>0.05)$ (Fig. 2). Such alterations were also observed in the study reported by Appidi et al. (2009) and Devaki et al. (2012) where Hermania incana leaves produced mild effect on haematological parameters. The haematological parameters like $\mathrm{HGB}, \mathrm{RBC}$ and PCV are linked with the total population of red cells; on the other hand $\mathrm{MCV}, \mathrm{MCH}$ and $\mathrm{MCHC}$ are associated with RBC alone. The in non-toxic effect of extract on these haematological parameters proposes that it does not regulate the inclusion of haemoglobin inside red cells and also do not alter the structural features and osmotic brittleness of red blood cells (Adebayo etal., 2005).

The aroma and flavour of $S$. aromaticum buds is due to the presence of volatile oil which is approximately 15 to $20 \%$. The main component phenylpropanoids consists of eugenol, carvacrol, cinnamaldehyde and thymol constitute $60-90 \%$ of distilled clove bud oil (Adam et al., 2013). Treatment with a foreign herbal compounds may bring about significant 


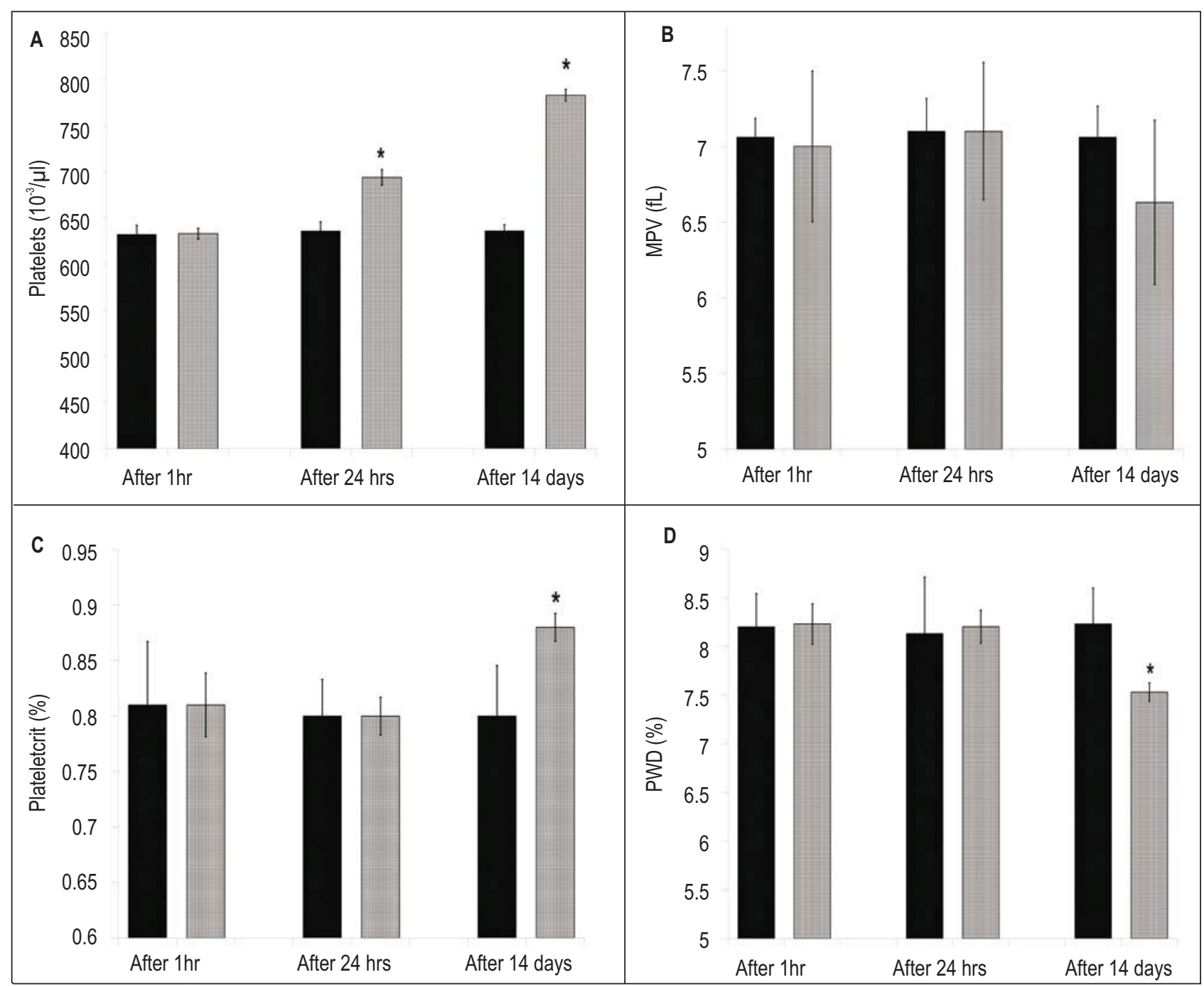

Control Treated

Fig. 2 : Effect of $S$. aromaticum hexane extract on platelet indices in rats. A : Platelets (PTL), B : Mean Platelet Volume (MPV), C : Plateletcrit (PCT) and D : Platelet Distribution Widths (PDWs). Values are mean \pm SD of three animals. *indicates significant difference $(P<0.05)$ between control and treated as obtained by Student's t-test

alterations in the metabolic conversion and concentration of enzymes, biomolecules and also in certain pathways (Oyewole et al., 2007). United States Food and Drug Administration declared clove oil as "Generally Regarded as Safe" substance when administered at a level of 1500 ppm in all food categories. Additionally the acceptable daily intake (ADI) of this oil was set as $2.5 \mathrm{mg} \mathrm{kg}^{-1}$ body weight for humans by WHO Expert Committee on food additives (Gulchin et al., 2012). It has been concluded that the rats exposed to hexane extract of $S$. aromaticum neither showed any signs of toxicity nor mortality during the course of study. Further the hexane extract of $S$. aromaticum did not induce any change on the blood profile of rats during short term exposure of 14 days.

\section{Acknowledgments}

Authors are grateful to Dr. Anil K. Misra and Dr. Krishna Chuttani (Division of Cyclotron and Radiopharmaceutical Sciences, Institute of Nuclear Medicine and Allied Sciences, Delhi) for providing help and support to carry out this research work. We also acknowledge Department of Biotechnology (DBT), Ministry of Science and Technology (Grant No. BT/254/NE/TBP/2011) for financial assistance.

\section{References}

Adam, S.I.Y., S.B. Mohamed and W.S. Abdelgadir: Effects of the aqueous extract of clove (Syzygium aromaticum) on Wistar rats. 
Brit. J. Pharmacol. Toxicol., 4, 262-266 (2013).

Adebayo, J.O., A.A. Adesokan, L.A. Olatunji, D.O. Buoro and A.O. Soladoye: Effect of ethanolic extract of Bougainvillea spectabilis leaves on haematological and serum lipid variables in rats. Biokemistri, 17, 45-50 (2005).

Agbaje, E.O., A.A. Adeneye and A.O. Daramola : Biochemical and toxicological studies of aqueous extract of Syzygium aromaticum (L.) Merry. and Perry (Myrtaceae) in rodents. Afr. J. Tradit. Complement. Altern. Med., 6, 241-254 (2009).

Aggarwal, B.B. and S. Shishodia : Molecular targets of dietary agents for prevention and therapy of cancer. Biochem. Pharmacol., 71, 13971421 (2006)

Al-Mamary, M.A.:Antioxidant activity of commonly consumed vegetables in Yemen. Mal. J. Nutr., 8, 179-189 (2002).

Appidi, J.R., M.T. Yakubu, D.S. Grierson and A.J. Afolayan: Toxicological evaluation of aqueous extracts of Hermannia incana Cav. leaves in male Wistar rats. Afr. J. Biotechnol., 8, 2016-2020 (2009).

Cai, L. and C.D. Wu : Compounds from Syzygium aromaticum possessing growth inhibitory activity against oral pathogens. J. Nat. Prod., 59, 987-990 (1996).

Chaieb, K., H. Hajlaoui, T. Zmantar, A.B. Kahla-Nakbi, M. Rouabhia, K. Mahdouani and A. Bakhrouf : The chemical composition and biological activity of clove essential oil, Eugenia caryophyllata (Syzygium aromaticum L. Myrtaceae): A short review. Phytother. Res., 21, 501-506 (2007).

Coles, E.H.: Veterinary Clinical Pathology. In: Comparative evaluation of the effects of velogenic newcastle disease virus infection on the hematology of ducks and chickens (Eds.: C.P. Eze, J.O.A. Okoye, I.O. Ogbonna, W.S. Ezema, D.C. Eze, E.C. Okwor, C. Okorie-Kanu and K.I. Idika) W.B. Saunders Co., Philadelphia, pp.17-19(1986).

Damiani, C.E., L.V. Rossoni and D.V. Vassallo: Vasorelaxant effect of eugenol on rat thoracic aorta. Vasc. Pharmacol., 40, 59-66 (2003).

De Gruchy, G.C.: Clinical haematology in Medical Practice. Blackwell Scientific Publication, Oxford, London, pp. 33-57 (1976).

Devaki, K., U. Beulah, G. Akila and V. K. Gopalakrishnan : Effect of aqueous extract of Passiflora edulis on biochemical and hematological parameters of Wistar albino rats. Toxicol. Int., 19, 63-67 (2012).

Dorman, H.J. and S.G. Deans: Antimicrobial agents from plants: Antibacterial activity of plant volatile oils. J. Appl. Microbiol., 88, 308-316 (2000).

Dudonne, S., X. Vitrac, P. Coutiere, M. Woillez and J.M. Merillon: Comparative study of antioxidant properties and total phenolic content of 30 plant extracts of industrial interest using DPPH, ABTS, FRAP, SOD, and ORAC assays. J. Agric. Food Chem., 57, 1768-1774 (2009).

Ekor, M.: The growing use of herbal medicines: Issues relating to adverse reactions and challenges in monitoring safety. Front. Pharmacol., 4, 1-10 (2014).

Ghosh, R., N. Nadiminty, J.E. Fitzpatrick, W.L. Alworth, T.J. Slaga and A.P. Kumar: Eugenol causes melanoma growth suppression through inhibition of E2F1 transcriptional activity. J. Biol. Chem., 280, 5812-5819(2005).

Gordon, S. and A. Pluddemann: Tissue macrophages : Heterogeneity and functions. BMC Biol., 15, 1-18 (2017).

Gulcin, I., M. Elmastas and H.Y. Aboul-Enein: Antioxidant activity of clove oil - A powerful antioxidant source. Arab. J. Chem., 5, 489-499 (2012).

Gulcin, I., I.G. Sat, S. Beydemir, M. Elmastas and O. I. Kufrevioglu: Comparison of antioxidant activity of clove (Eugenia caryophylata
Thunb) buds and lavender (Lavandula stoechas L.). Food Chem., 87, 393-400 (2004).

Halder, S., A.K. Mehta, R. Kar, M. Mustafa, P.K. Mediratta and K.K. Sharma: Clove oil reverses learning and memory deficits in scopolamine-treated mice. Planta. Med., 77, 830-834 (2011).

Imoru, J.O., A.E. Eno, F.B. Unoh, E. ENkanu, O.E. Ofem and J.O. Ibu: Haematopoietic agents in the crude extracts from the leaves of Viscum album (mistletoe). Niger. J. Hith. Biomed. Sci., 4, 139-145 (2005).

Jadhav B.K., K.R. Khandelwal, A.R. Ketkar and S.S. Pisal: Formulation and evaluation of mucoadhesive tablets containing eugenol for the treatment of periodontal diseases. Drug. Dev. Ind. Phar., 30, 195203 (2004).

Kamatou, G.P., I. Vermaak and A.M. Viljoen: Eugenol--from the remote Maluku Islands to the international market place: A review of a remarkable and versatile molecule. Molecules, 17, 6953-6981 (2012).

Ladokun, O., M. Ojezele and O. Arojojoye: Comparative study on the effects of aqueous extracts of Viscum album (mistletoe) from three host plants on hematological parameters in albino rats. Afr. Hlth. Sci., 15, 606-612(2015).

Nadkarni, K.M.: Myrtus caryophyllus. In: Materia Medica (Ed.: K.M. Nadkarni). Popular Prakashan Pvt. Ltd., Mumbai, India, pp: 835$836(2000)$.

Oyedemi, S.O., E.A. Adewusi, O.A. Aiyegoro and D.A. Akinpelu: Antidiabetic and haematological effect of aqueous extract of stem bark of Afzelia africana (Smith) on streptozotocin-induced diabetic Wistar rats. Asian Pac. J. Trop. Biomed., 1, 353-358 (2011).

Oyewole, I.O., Z.J. Magaji and O.A. Awoyinka: Biochemical and toxicological studies of aqueous extract of Tithonia diversifolia (hemsl.) leaves in Wistar albino rats. J. Med. Plants Res., 1, 030033 (2007).

Olson, H., G. Betton, D. Robinson, K. Thomas, A. Monro, G. Kolaja, P. Lilly, J. Sanders, G. Sipes, W. Bracken, M. Dorato, K. V. Deun, P. Smith, B. Berger and A. Heller : Concordance of the toxicity of pharmaceuticals in humans and in animals. Regul. Toxicol. Pharmacol., 32, 56-67 (2000).

Parma, M.J., A. Loteste, M. Campana and C. Bacchetta : Changes of hematological parameters in Prochilodus lineatus (Pisces, Prochilodontidae) exposed to sublethal concentration of cypermethrin. J. Environ. Biol., 28, 147-149 (2007).

Petrovska, B.B.: Historical review of medicinal plants' usage. Pharmacogn Rev., 6, 1-5 (2012).

Rana, I.S., A.S. Rana and R.C. Rajak: Evaluation of antifungal activity in essential oil of the Syzygium aromaticum (L.) by extraction, purification and analysis of its main component eugenol. Braz. J. Microbiol., 42, 1269-1277 (2011).

Sanchez-Elsner, T., J.R. Ramirez, F. Sanz-Rodriguez, E. Varela, C. Bernabeu and L.M. Botella: A cross-talk between hypoxia and TGF-beta orchestrates erythropoietin gene regulation through SP1 and Smads. J. Mol. Biol., 336, 9-24 (2004).

Shan, B., Y.Z. Cai, M. Sun and H. Corke:Antioxidant capacity of 26 spice extracts and characterization of their phenolic constituents. $J$. Agric. Food Chem., 53, 7749-7759 (2005).

Sofia, P.K., R. Prasad, V.K. Vijay and A.K. Srivastava: Evaluation of antibacterial activity of Indian spices against common foodborne pathogens. Int. J. Food Sci. Tech., 42, 910-915 (2007).

Vijayasteltar, L., G.G. Nair, B. Maliakel, R. Kuttan and I.M. Krishnakumar: Safety assessment of a standardized polyphenolic extract of clove buds: Subchronic toxicity and mutagenicity studies. Toxicol. Rep., 3,439-449 (2016). 